\title{
ESTUDO ANATÔMICO DO LENHO E DESCRIÇÃO BOTÂNICA DE RHAMNUS SPHAEROSPERMA SWARTZ (RHAMNACEAE). ${ }^{1}$
}

\author{
SIDINEI RODRIGUES DOS SANTOS² JOSÉ NEWTON CARDOSO MARCHIORI ${ }^{3}$ \\ THAIS SCOTTIDO CANTO-DOROW ${ }^{4}$ LUCIANO DENARDI $^{5}$
}

\section{RESUMO}

O presente trabalho trata da descrição botânica e anatomia da madeira de Rhamnus sphaerosperma Swartz (Rhamnaceae), com base em material proveniente do Rio Grande do Sul - Brasil. A estrutura anatômica da madeira concorda, em linhas gerais, com o referido na literatura para o gênero Rhamnus e família Rhamnaceae. A ausência de arranjo dendrítico ou em zig-zag, bem como a porosidade semi-difusa, observadas na madeira, confirmam a inserção da espécie no subgênero Frangula, concordando, neste aspecto, com o ponto de vista taxonômico, baseado na morfologia externa.

Palavras-chave: Rhamnus sphaerosperma, Rhamnaceae, Anatomia da Madeira.

\section{SUMMARY}

[Wood anatomy and botanic description of Rhamnus sphaerosperma Swartz (Rhamnaceae)]. This paper deals with the botanical description and wood anatomy of Rhamnus sphaerosperma Swartz (Rhamnaceae), based on materials from the state of Rio Grande do Sul - Brazil. The anatomical structure agrees with literature references to genus Rhamnus and family Rhamnaceae. The absence of dendritic or zigzag pore pattern, as well as the semi-diffuse porosity, insert the species in the subgenus Frangula, in agree with the taxonomical point of view, based on external morphology.

Keywords: Rhamnus sphaerosperma, Rhamnaceae, Wood Anatomy.

\section{INTRODUÇÃO}

De distribuição cosmopolita, o conjunto das Rhamnaceae compreende cerca de 50 gêneros e 900 espécies (Souza \& Lorenzi, 2005). Com 8 dos 13 gêneros e 9 das 50 espécies nativas no Brasil, o Rio Grande do Sul é o estado melhor representado; cabe destacar, entretanto, o caráter relictual destas espécies (quase todos os gêneros representados por apenas uma espécie) e sua notável diversidade de hábito que, em formas muito peculiares, inclui árvores pequenas, arbustos xerófilos e até trepadeiras lenhosas, integrantes de formações campestres e estratos inferiores ou orla de florestas.

De distribuição cosmopolita, o gênero Rhamnus L. compreende umas 160 espécies de porte arbóreo ou arbustivo, inermes ou com ramos transformados em espinhos, com folhas alternas, pecioladas, e flores 4-5meras, com disco delgado, forrando o receptáculo; os frutos, drupáceos, reúnem 2-4 caroços monospérmicos (Tortosa, 1995). Em sua revisão das espécies neotrópicas, Johnston \& Johnston (1978) reconhecem dois subgêneros: Rhamnus e Frangula,

1 Artigo recebido em 15/4/2007 e aceito para publicação em 30/4/2007.

${ }^{2}$ Biólogo, bolsista do CNPq - Brasil, mestrando do Programa de Pós-Graduação em Engenharia Florestal, Centro de Ciências Rurais, Universidade Federal de Santa Maria, CEP 97105-900, Santa Maria (RS). sthurt.bio@gmail.com

${ }^{3}$ Engenheiro Florestal, Dr., Bolsista de Produtividade em Pesquisa do CNPq - Brasil, Professor Titular do Departamento de Ciências Florestais, Universidade Federal de Santa Maria, CEP 97105-900, Santa Maria (RS). balduinia (a) mail.ufsm.br

${ }^{4}$ Bióloga, Dra., Departamento de Biologia, Universidade Federal de Santa Maria (RS), CEP 97105-900. thaisdorow@smail.ufsm.br

${ }^{5}$ Engenheiro Florestal, bolsista do $\mathrm{CNPq}$ - Brasil, M. Sc., doutorando do Programa de Pós-Graduação em Engenharia Florestal, Universidade Federal de Santa Maria, CEP 97105-900, Santa Maria (RS). lucianodenardi@yahoo.com.br 
pertencendo a este último quase todas as espécies estudadas pelo autor, inclusive a tratada no presente trabalho.

Nativa da Costa Rica até o sul do Brasil e norte da Argentina, incluindo Paraguai, Bolívia, Peru, Colômbia e Venezuela (Tortosa, 1995), Rhamnus sphaerosperma é o único representante do gênero no País (Johnston \& Johnston, 1972).

Além da região sul, Souza \& Lorenzi (2005) também assinalam a sua presença no sudeste do Brasil, onde ocorre, com freqüência, em florestas alagáveis. Espécie heliófila e seletiva higrófila, habita regiões serranas do Rio Grande do Sul, em solos geralmente úmidos, arenosos com húmus ou pedregosos, ocorrendo preferencialmente na orla de capões e matas, menos freqüentemente em seu interior, e até em beira de estradas (Bastos, 1993). Característica da Floresta Ombrófila Mista sul-brasileira, a espécie é considerada "elemento andino" (Rambo, 1951) ou "holártico" (Marchiori, 2006), nesta formação.

Conhecida vulgarmente como cangica ou cangiqueira, no Brasil (Corrêa, 1926), e como picantillo, na Argentina (Tortosa, 1995), Rhamnus sphaerosperma fornece madeira um pouco elástica, própria para fabricação de cabos de ferramentas; é também usada localmente como lenha (Corrêa, 1926). Várias espécies do gênero são empregadas em farmacologia, na extração de corantes para tinturaria, como plantas ornamentais, alimentícias (frutos) e, até mesmo, na preparação de bebidas fermentadas (Marzocca \& Marthi, 1951).

Com relação a Anatomia da Madeira, Metcalfe \& Chalk (1972), relacionam para o conjunto das Ramnáceas as seguintes características anatômicas: vasos tipicamente pequenos, ocasionalmente grandes em algumas espécies, comumente em múltiplos e com arranjo tendente a radial; porosidade em anel e vasos de lenho tardio com espessamentos espiralados em muitos gêneros; placas de perfuração simples; pontoações intervasculares alternas, de bor- das diminutas a grandes; elementos vasculares de comprimento médio a moderadamente curtos; parênquima predominantemente paratraqueal na maioria das espécies, dos tipos vasicêntrico, aliforme ou confluente; parênquima apotraqueal ou intermediário, em poucas espécies; raios predominantemente de 2-5 células de largura, mas consideravelmente largos em algumas espécies e exclusivamente unisseriados, em outras; raios marcadamente heterogêneos até homogêneos, por vezes compostos inteiramente de células quadradas e eretas; fibras com pontoações simples, de comprimento médio a moderadamente curtas; e traqueídeos vasculares presentes em espécies com vasos em arranjo diagonal ou dendrítico.

Para o gênero Rhamnus, Record (1939) destaca: anéis de crescimento presentes; madeira com porosidade em anel; poros pequenos a diminutos, numerosos, diminuindo gradualmente em tamanho; a maior parte em curtos a longos múltiplos, algumas vezes em pequenos agrupamentos, sem padrão definido no lenho tardio em Frangula; de tamanho uniforme e em padrão conspícuo em todo anel de crescimento em Eurhamnus; vasos com espessamentos espiralados; raios de 1-3, algumas vezes 4 células de largura; até 40, comumente menos que 25 células de altura; heterogêneos em parte; cristais comuns; pontoações intervasculares pequenas; parênquima axial muito escassamente paratraqueal; fibras com paredes finas a médias, em Frangula, espessas a muito espessas em Eurhamnus; camada interna gelatinosa freqüentemente presente, até mesmo em fibras com paredes de espessura moderada.

Segundo Record \& Ress (1949), as espécies do gênero Rhamnus podem ser agrupadas em dois subgêneros (Frangula e Eurhamnus), que são mais distintos entre si do que a maioria dos outros gêneros da família: no subgênero Eurhamnus, as madeiras têm porosidade difusa e os poros, muito pequenos a diminutos, compõem múltiplos em arranjo dendrítico ou zig-zag; no subgênero Frangula, as madeiras têm 
porosidade mais ou menos em anel, e os poros, embora nunca grandes, diminuem gradualmente de tamanho, em direção ao término do anel de crescimento.

De acordo com Record \& Ress (1949), as madeiras de Rhamnus apresentam: cor amarela, laranja ou marrom-alaranjada; alburno distinto, mas freqüentemente não bem demarcado; brilho médio; odor e sabor ausentes ou não distintos; densidade muito baixa até média (em Frangula), muito alta em Eurhamnus; textura média; grã reta a irregular; fácil trabalhabilidade; durabilidade média a boa; e ausência de importância comercial, devido à pequena dimensão dos troncos.

\section{MATERIAL E MÉTODOS}

O material estudado consiste de duas amostras de madeira e exsicatas provenientes dos principais Herbários do Rio Grande do Sul, além de material botânico obtido durante viagens de coleta.

As amostras de madeira, conservadas na Xiloteca do Departamento de Ciências Florestais da Universidade Federal de Santa Maria, dispõem das seguintes informações:

- Marchiori, J. N. C., sn., X.2005. Rhamnus sphaerosperma, amostra n.1. Floresta Nacional de São Francisco de Paula (FLONA), RS.

- Marchiori, J. N. C., sn., X.2005. Rhamnus sphaerosperma, amostra n.2. Floresta Nacional de São Francisco de Paula (FLONA), RS.

As exsicatas examinadas para descrição botânica integram os acervos do HDCF (Herbário do Departamento de Ciências Florestais, Universidade Federal de Santa Maria, RS), PEL (Herbário do Departamento de Botânica, Universidade Federal de Pelotas, RS), PACA (Herbarium Anchieta, Unisinos, São Leopoldo, RS) e SMDB (Herbário do Departamento de Biologia, Universidade Federal de Santa Maria, RS).

A descrição botânica foi realizada mediante análise do referido material e de observações das populações naturais no campo, respeitando as diferentes procedências e toda variabilidade morfológica observada na espécie.

A terminologia utilizada para a descrição baseia-se em Radford et alii. (1974). A análise morfológica das estruturas foi realizada com auxílio da lupa binocular Olympus SZ40, régua de precisão $(0,5 \mathrm{~mm})$ e papel milimetrado. Informações relativas ao porte, fenologia, coloração e consistência de estruturas, foram obtidas a partir de observações a campo e de anotações contidas nas etiquetas de identificação das exsicatas. Os demais aspectos são apresentados segundo a literatura.

Para descrição anatômica da madeira, foram preparadas lâminas de cortes anatômicos e de macerado.

Das referidas amostras de madeira, foram extraídos três corpos de prova $(3 \times 3 \times 3 \mathrm{~cm})$ da parte mais externa do lenho, próximo ao câmbio, orientados para obtenção de cortes anatômicos nos planos transversal, longitudinal radial e longitudinal tangencial. Um outro bloco foi também retirado, com vistas à maceração. Para a produção de lâminas de cortes anatômicos, seguiu-se a técnica padrão no Laboratório de Anatomia da Madeira da Universidade Federal do Paraná: as amostras foram amolecidas por fervura em água e seccionadas em micrótomo de deslizamento, regulado para a obtenção de cortes com espessura nominal de $20 \mu \mathrm{m}$. Os cortes foram tingidos com acridinavermelha, crisoidina e azul-de-astra (Dujardin, 1964), desidratados em série alcoólica-ascendente $(30 \%, 50 \%, 70 \%, 95 \%$ e duas vezes em álcool absoluto), diafanizados em xilol e montados em lâminas permanentes, usando-se "Entellan" como meio de montagem.

Para a confecção de lâminas de macerado, utilizou-se o método de Jeffrey (Burger \& Richter, 1991), sendo a pasta resultante colorida com solução aquosa $1 \%$. A montagem das lâminas seguiu o método anteriormente descrito, com a diferença de que a primeira etapa foi desenvolvida sobre papel de filtro.

A descrição microscópica da madeira seguiu as recomendações da Copant (1973). Os 
valores quantitativos, apresentados na Tabela 1 , são resultantes de 30 medições, com exceção da percentagem dos tipos celulares e das classes de raio, para os quais foram realizadas 600 determinações ao acaso, usando-se contador de laboratório modelo Leucodiff 105; a freqüência de poros $/ \mathrm{mm}^{2}$ foi obtida de forma indireta, a partir de um quadrado vazado de área conheci$\mathrm{da}$, superposto a fotomicrografias de seção transversal. Na determinação do percentual dos diferentes tipos celulares e classes de raios, seguiu-se a metodologia proposta por Marchiori (1980). As medições foram realizadas em microscópio binocular Carl Zeiss, provido de ocular com escala graduada, no laboratório de Anatomia da Madeira da Universidade Federal de Santa Maria. As fotomicrografias foram tomadas em microscópio Olympus cx40, equipado com câmera digital Olympus Camedia c3000, no Laboratório de Anatomia da Madeira da Universidade Federal do Paraná. As ilustrações, apresentadas na Figura 1, são obra de Leonardo Paz Deble, a quem os autores agradecem.

\section{DESCRIÇÃO BOTÂNICA}

\section{Rhamnus sphaerosperma Swartz}

Prod. Veg. Ind. Occ. 50. 1788.

Arbustos ou arvoretas com até $5 \mathrm{~m}$ de altura, de tronco pouco desenvolvido, ramificado; casca áspera, acinzentada; ramos, folhas e demais órgãos, de moderadamente até muito pilosos, por vezes tomentosos, sobretudo quando jovens; tricomas de tamanho variável, amarelos, com queda não uniforme nos ramos, freqüentemente formando tufos em determinadas regiões. Ramos pouco numerosos, delgados, cilíndricos, alternos, ascendentes; os mais jovens, floríferos e folhosos (porções distais), glabrescentes com a idade (Figura 1a). Folhas persistentes, simples, alternas, pecioladas, verde-claras, membranáceas a sub-coriáceas, com tricomas geralmente mais abundantes sobre a face abaxial, especialmente sobre as nervuras; face adaxial quase glabra (tricomas restritos as nervuras) a mode- radamente pilosa, por vezes muito pilosa; limbo reticulado, elíptico, de 4,5-12,5 cm de comprimento por 2,3-5,8 cm de largura, não raro com glândulas sésseis arredondadas, escurecidas, escassas; ápice caudado, acuminado, até breve-acuminado; base geralmente cuneada ou arredondada; margem serreada ou serrilhada, com dentes de diferentes tamanhos, terminados por glândulas diminutas, não evidentes; nervuras braquidódromas, predominantemente alternas ou subopostas, oblíquas, paralelas e interligadas por denso retículo de finas nervuras, salientes na face inferior e geralmente imersas na superior. Pecíolos canaliculados na parte superior, de 0,5$2 \mathrm{~cm}$ de comprimento. Estípulas laminares, caducas; as foliares, com 2,0-5,8 mm de comprimento, pareadas; as florais, menores de $2 \mathrm{~mm}$. Flores perfeitas, períginas, pentâmeras, de simetria radial, pequenas $(5-10 \mathrm{~mm}$ de altura por 2,5-4 mm de diâmetro) e reunidas, nos ramos jovens, em fascículos, cimas ou panículas umbeliformes contraídas, axilares, curtopedunculadas, geralmente com 5-10 ou até mais de 15 flores (Figura 1a-c). Pedicelos longos (1,7-5,8 mm de comprimento). Receptáculo floral obcônico ou campanulado, de 1,2-2 mm de altura (Figura 1b). Lacínias triangulares, eretas, de 1,3-1,7 mm de altura, carnosas, com nervura longitudinal-ventral espessa (figura 1d). Pétalas livres, envolvendo os estames, cuculadas, ungüiculadas, de ápice bilobado, com alguma pilosidade no dorso, alternas e menores que as sépalas (cerca de $2 / 3$ de sua altura), inseridas entre o bordo do receptáculo e o disco (Figura 1c, e, e'). Disco nectarífero carnoso, delgado, glabro e de margem curva, forrando a parede interna do receptáculo (Figura 1c). Estames livres, opostos às pétalas, dorsifixos; anteras rostradas, com deiscência longitudinal; filetes laminares, ao menos em material seco, expandidos do disco (Figura 1c,f). Ovário súpero, subgloboso, glabro, tricarpelar, trilocular, com um óvulo por lóculo; estilete curto ou, mais freqüentemente, longo, não exserto; estigma trilobado (figura 1c). Fruto glabro, do tipo 


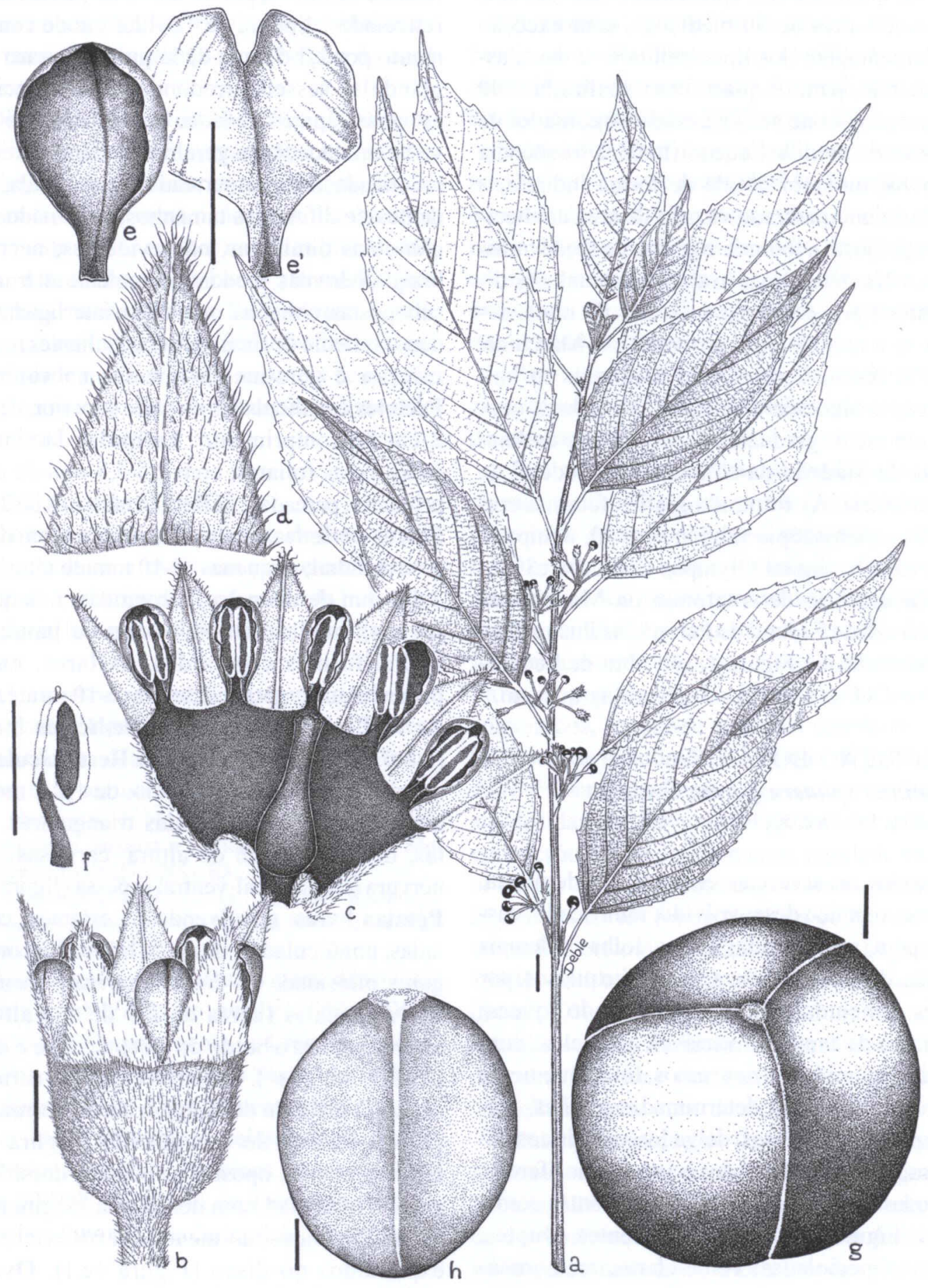

FIGURA 1. Ramo florido de Rhamnus sphaerosperma Swartz (a). Flor (b). Disco (c). Sépala (d). Pétala (e). Pétala aberta $\left(e^{\prime}\right)$. Estame (f). Fruto (g). Caroço (h). $\left(\mathrm{a}=1 \mathrm{~cm} ; \mathrm{b}, \mathrm{c}, \mathrm{d}, \mathrm{e}, \mathrm{e}^{\prime}, \mathrm{f}, \mathrm{h}=1 \mathrm{~mm}\right)$. 
pirênio, com três caroços monospérmicos, em geral mais ou menos esférico, ligeiramente tricoco em vista frontal, lenhoso quando seco e com 4,0-9,0 mm de diâmetro (Figura 1g); caroços arredondados ou abovados em vista longitudinal, convexos no dorso e ligeiramente angulosos na parte ventral (Figura 1h).

Etimologia: O nome genérico vem do grego rhamnos, com origem no celta ram, que significa arbusto. O termo sphaerosperma alude aos frutos quase esféricos (Johnston \& Soares, 1972).

Fenologia: Floresce de outubro a dezembro e frutifica de dezembro a fevereiro.

Material examinado: BRASIL: RIO GRANDE D0 SUL: Bom Jesus, in silvula campestri, fr. maturo, B. Rambo s.n., 15.I.1942 (PACA 8785); in araucarieto, fr. maturo, B. Rambo s.n., 16.I.1942 (PACA 9071); Serra da Rocinha, in silvula campestris, ster., B.Rambo s.n., 14.II.1947 (PACA 35299). Cambará do Sul, Itaimbezinho, arvoreta ca. de $4 \mathrm{~m}$, em borda de mata com Araucária, flores brancas, frutos imaturos, verdes, J. A. Jarenkow \& R.M. Bueno 1141, 27.XII.1988 (PEL 11208); Taimbezinho, p. São Francisco de Paula, in araucarieto, fr. submaturo, B. Rambo s.n., 30.I.1950 (PACA 45509); ibidem, in araucarieto, fl., B. Rambo s.n., 18.XII.1950 (PACA 49353); ibidem, in araucarieto, fr. maturo, B. Rambo s.n., 21.II.1951 (PACA 50073); ibidem, arbor parva in silva (araucarieto), 900 m.s.m., A. Sehnem s.n., 2.XI.1965 (PACA 81538); ibidem, arbor in silva campestris, fr., A. Sehnem s.n., 17.I.1963 (PACA 81539). Faxinal, com flores, M. Sobral 2790, XII.1983 (PEL 12725); p. São Francisco de Paula, in araucarieto, fr. maturo, B. Rambo s.n., II.1948 (PACA 36362). Caxias, in araucarieto, fr. maturo, Ir. Augusto s.n., II.1932 (PACA 11847); Vila Oliva, in araucarieto, fr., B. Rambo s.n., 4.I.1946 (PACA 31039). Esmeralda, Est. Ecol. de Aracuri., no capoeirão, arvoreta, J. Mauhs s.n., s.d., (PACA 86515); ibidem, arvoreta na capoeira, J. Mauhs s.n., 3.XII.2002 (PACA 91984). Garibaldi, in dumetosis, flores imaturas, Camargo 2251, 29.X.1957 (PACA61827). Nova Petrópolis, p. Caí, in araucarieto, fr., B. Rambo s.n., I.1943 (PACA 11118). Passo Fundo, FLONA, com flores, S.J. Longhi s.n., 03.XI.1981 (HDCF 79); ibidem, com flores, Longhi \& Marchiori s.n., 12.XI.1976 (HDCF 382); ibidem, com flores imaturas, Longhi \& Marchiori s.n., 06.X.1980 (HDCF 66); ibidem, com frutos, S.J. Longhi s.n., 16.XII.1976 (HDCF 390); ibidem, com flores, J.N.C. Marchiori \& Longhi s.n., 07.XI.1985 (HDCF 1897); ibidem, com frutos, Marchiori \& Longhi s.n., 15.I.1981 (HDCF 180). São Francisco de Paula, in araucarieto, fl., A. Sehnem 5104, 18.XII.1950 (PACA 50989); Faz. p. São Franciso de Paula, in araucarieto, fr. maturo, P. Buck s.n., 6.I.1935 (PACA 1821); FLONA, com frutos, A. Simionato s.n., II.1977 (HDCF 1062); ibidem, estéril, A.A. Filho s.n., 25-30.IX.1995 (SMDB 5648); ibidem, orla de mata com araucária, J. Mauhs s.n., 27.X.1994 (PACA 87455); Tainhas, p. São Francisco de Paula, in araucarieto, ster., B. Rambo s.n., 16.II.1946 (PACA 32253). São José dos Ausentes, próximo ao arroio Silveira, na beira da estrada, em borda de mata com Araucária, arvoreta ca. $4 \mathrm{~m}$, folhas membranáceas, verde-claras, flores imaturas, J. N. C. Marchiori \& S. R. Santos s.n., 27.X.2006 (HDCF 5715). Vacaria, Faz. da Ronda, in araucarieto, fr. submaturo, B. Rambo s.n., 10.I.1947 (PACA 34934); Faz. Pedro Vieira, orla de mata com araucária, J. Mauhs s.n., 10.XI. 1998 (PACA 85200); Passo do Socorro, p. Vacaria, in araucarieto, fr. novo, B. Rambo s.n., 28.XII.1951 (PACA 51691).

Material adicional:: BRASIL: SANTA CATARINA: São Joaquim, Distrito de Pericó, próximo ao rio Pericó, com frutos, L. P. Deble \& A. S. Oliveira s.n., 5.XII.2003 (HDCF 5714). PARANÁ: Santo Antônio do Paraíso, Sítio Yoshida, arbusto ca. $2,5 \mathrm{~m}$, flores brancas, L. I. Demarchi et al. s.n., 25.IX.1997 (SMDB 7316). São João do Triunfo, popular cangica, com flores, S. J. Longhi s.n., 8.XI.1979 (HDCF 652). Tunas do Paraná, arredores, arvoreta ca. $5 \mathrm{~m}$, em mata secundária, frutos maduros vermelhos, J. M. Cruz \& L. M. Abe 43, 15.XII.1998 (SMDB 7271).

\section{DESCRIÇÃO DA MADEIRA}

Anéis de crescimento distintos (Figura 2A), evidenciados pela concentração de fibras radialmente estreitas no lenho tardio, bem como pelo contraste dos vasos de pequeno diâmetro, no referido lenho, e os de diâmetro nitidamente maior, no lenho inicial, caracterizando uma porosidade semi-difusa (Figura 2A).

Vasos numerosíssimos $\left(25-44-75 / \mathrm{mm}^{2}\right)$, ocupando $12,2 \%$ do volume da madeira; solitários, em múltiplos radiais de 2 a 6 e em múltiplos racemiformes (Figura 2A, B). Poros de secção poligonal até oval, pequenos $(22-46-90 \mu \mathrm{m})$, de paredes finas $(2,5-3,0-3,8 \mu \mathrm{m})$, e freqüentemente com conteúdos (Figura 2A), no cerne. Elementos vasculares muito curtos até curtos (220-389$650 \mu \mathrm{m}$ ), com placas de perfuração simples (Figura 2D), espessamentos espiralados na parede (Figura 2F) e apêndices curtos (10-61-182 $\mu \mathrm{m}$ ), 
TABELA 1: Dados quantitativos da madeira.

\begin{tabular}{|c|c|c|c|c|}
\hline Característica anatômica & mín. & média & máx. & $\mathrm{s}$ \\
\hline Fração de poros (\%) & 7,0 & 12,2 & 19 & 3,56 \\
\hline Freqüência de poros (poros $/ \mathrm{mm}^{2}$ ) & 25 & 44 & 75 & 15,07 \\
\hline$\varnothing$ total dos poros $(\mu \mathrm{m})$ & 22 & 46 & 90 & 15,34 \\
\hline$\varnothing$ do lume dos poros $(\mu \mathrm{m})$ & 17,5 & 39 & 82 & 15,15 \\
\hline Espessura da parede dos poros $(\mu \mathrm{m})$ & 2,5 & 3,0 & 3,8 & 0,62 \\
\hline Comprimento de elementos vasculares $(\mu \mathrm{m})$ & 220 & 389 & 650 & 72,37 \\
\hline Comprimento de apêndices $(\mu \mathrm{m})$ & 10 & 61 & 182 & 39,48 \\
\hline$\varnothing$ das pontoações intervasculares $(\mu \mathrm{m})$ & 6 & 7,9 & 10 & 1,05 \\
\hline$\emptyset$ das pontoações raio-vasculares $(\mu \mathrm{m})$ & 3 & 5,1 & 7 & 0,75 \\
\hline$\varnothing$ das pontoações parênquimo-vasculares $(\mu \mathrm{m})$ & 4 & 4,8 & 6 & 0,61 \\
\hline Fração de parênquima axial (\%) & 3 & 4,9 & 8 & 1,44 \\
\hline Altura das séries de parênq. axial $(\mu \mathrm{m})$ & 200 & 389 & 575 & 84,74 \\
\hline Altura das séries de parênq. axial (células) & 2 & 5 & 8 & 2,03 \\
\hline Altura das células de parênquima axial $(\mu \mathrm{m})$ & 15 & 78 & 187 & 36,27 \\
\hline Largura das células de parênquima axial $(\mu \mathrm{m})$ & 7,5 & 14 & 20 & 2,72 \\
\hline Fração de raios $(\%)$ & 8 & 12,2 & 18 & 3,27 \\
\hline Freqüência de raios (raios/mm) & 6 & 9 & 14 & 1,76 \\
\hline Fração de raios unisseriados $(\%)$ & 7 & 17,5 & 30 & 8,22 \\
\hline Altura de raios unisseriados $(\mu \mathrm{m})$ & 37 & 115 & 463 & 69,46 \\
\hline Altura de raios unisseriados (células) & 1 & 5 & 19 & 3.10 \\
\hline Largura de raios unisseriados $(\mu \mathrm{m})$ & 7,5 & 12,5 & 20 & 2,56 \\
\hline Altura de raios multisseriados $(\mu \mathrm{m})$ & 93 & 336 & 788 & 146,83 \\
\hline Altura de raios multisseriados (células) & 5 & 19 & 50 & 8,85 \\
\hline Largura de raios multisseriados $(\mu \mathrm{m})$ & 12,5 & 34 & 70 & 10,41 \\
\hline Largura de raios multisseriados (células) & 2 & 4 & 5 & 0,89 \\
\hline Fração de raios bisseriados (\%) & 13 & 17,4 & 26 & 3,60 \\
\hline Fração de raios trisserriados $(\%)$ & 11 & 17,7 & 28 & 5,15 \\
\hline Fração de raios tetrasseriados (\%) & 19 & 34,9 & 56 & 10,80 \\
\hline Fração de raios c/ mais de 4 células & 5 & 12,5 & 23 & 6,39 \\
\hline Fração de fibras (\%) & 63 & 70,7 & 79 & 4,11 \\
\hline Comprimento de fibras $(\mu \mathrm{m})$ & 330 & 589 & 860 & 112,53 \\
\hline$\varnothing$ total das fibras $(\mu \mathrm{m})$ & 10 & 18 & 23 & 2,76 \\
\hline$\varnothing$ do lume das fibras $(\mu \mathrm{m})$ & 2,5 & 9,6 & 17,5 & 3,06 \\
\hline Espessura da parede das fibras $(\mu \mathrm{m})$ & 2,5 & 4,0 & 6,2 & 0,96 \\
\hline
\end{tabular}

$\mu \mathrm{m}=$ micrômetros; $\varnothing=$ diâmetro; parênq. = parênquima; mín.= valor mínimo; máx = valor máximo; $\mathrm{s}=$ desvio padrão. 

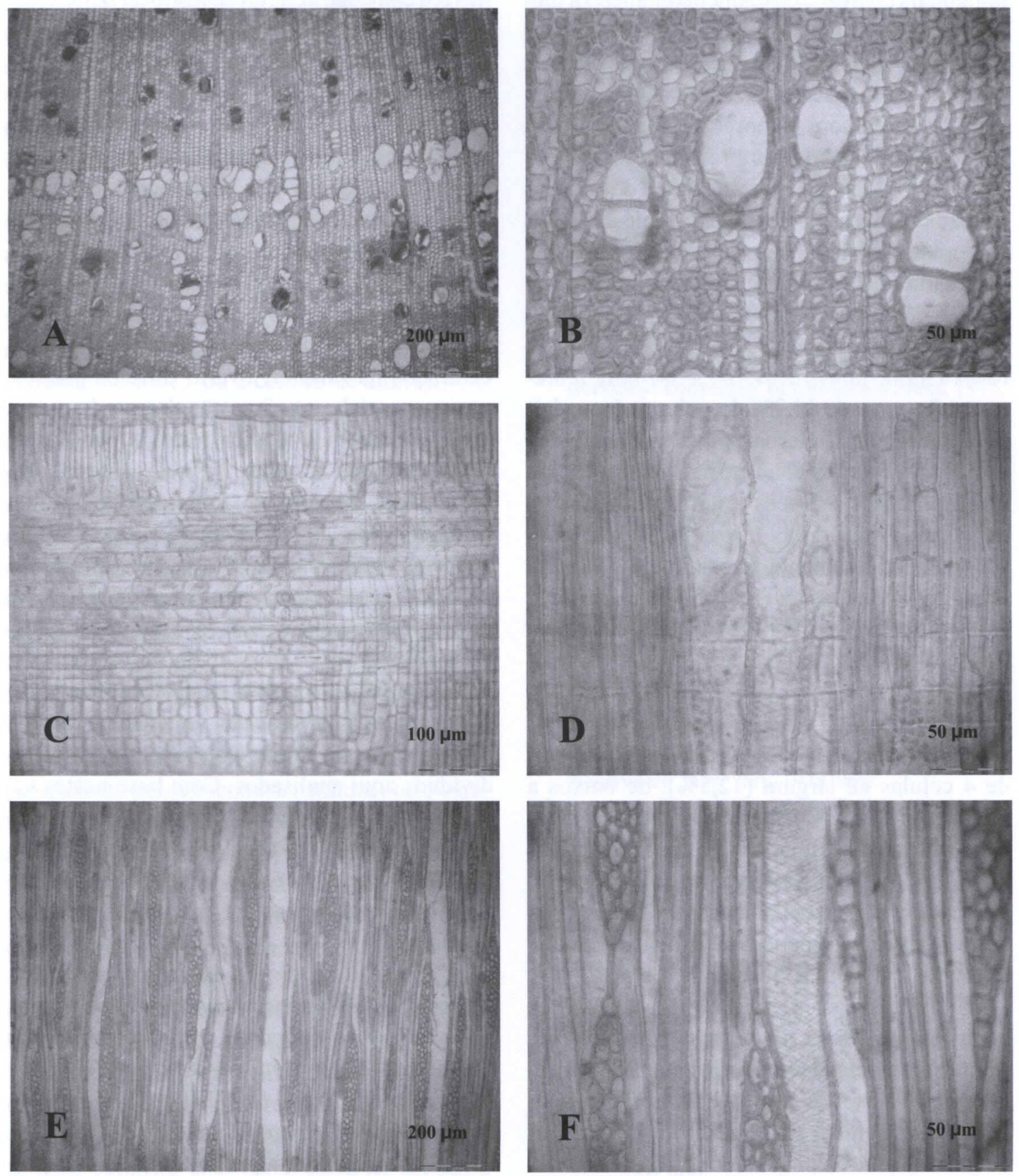

FIGURA 2. Aspectos anatômicos da madeira de Rhamnus sphaerosperma. Anéis de crescimento distintos, porosidade semi-difusa e poros freqüentemente com conteúdos (A). Poros em múltiplos radiais, parênquima paratraqueal escasso e fibras gelatinosas (B). Raio heterogêneo (C). Placa de perfuração simples (D). Raios não estratificados (E). Raios multisseriados com 2-5 células de largura, elemento vascular com espessamentos espiralados e pontoações alternas (F). 
geralmente em ambas as extremidades. Pontoações intervasculares alternas (Figura 2F), poligonais ou ovais, de diâmetro pequeno a médio $(6,0-7,8-10 \mu \mathrm{m})$ e com abertura lenticular, horizontal, inclusa. Pontoações raio-vasculares e parênquimo-vasculares semelhantes às intervasculares, embora menores.

Parênquima axial paratraqueal escasso (Figura 2B), ocupando cerca de 4,9\% do volume da madeira. Séries parenquimáticas de 200-389$575 \mu \mathrm{m}$ e $2-5-8$ células de altura; células parenquimáticas axiais de $15-78-187 \mu \mathrm{m}$ de altura e 7,5-14-20 $\mu \mathrm{m}$ de largura.

Raios não estratificados (Figura 2E), numerosos a muito numerosos $(6-9,4-14 / \mathrm{mm})$, representando cerca de $12,2 \%$ do volume da madeira. Tecido radial heterogêneo (Figura 2C) tipo II, com células procumbentes na parte multisseriada e margens relativamente curtas, de células quadradas e eretas. Raios unisseriados extremamente finos $(7,5-12,5-20 \mu \mathrm{m})$,

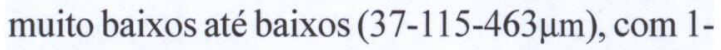
5-19 células em altura; raios multisseriados com 2-5 células de largura (Figura 2F), em sua maioria tetrasseriados $(34,9 \%$ do total $)$, freqüentemente tri e bisseriados (17,7 e 17,4\%, respectivamente), menos comumente com mais de 4 células de largura (12,5\%); de baixos a medianos (93-336-788 $\mu \mathrm{m})$, com 5-19-50 células de altura, e de muito finos a estreitos (12,534-70 $\mu \mathrm{m}$ ). Células envolventes, esclerosadas, latericuliformes, mucilaginosas e oleiferas, ausentes; cristais prismáticos de oxalato de cálcio, presentes em células quadradas e eretas.

Tecido fibroso proeminente (63-70,7-79\%), composto de fibras libriformes não septadas, freqüentemente gelatinosas (Figura 2B); extremamente curtas a muito curtas (330-590$860 \mu \mathrm{m})$, estreitas $(10-18-23 \mu \mathrm{m})$ e de paredes delgadas $(2,5-4-6,2 \mu \mathrm{m})$.

Canais secretores, tubos laticíferos e taniníferos, líber incluso e estratificação, ausentes; máculas medulares não observadas.

\section{DISCUSSÃO}

A identidade botânica do material em estudo merece comentário, a fim de justificar o não reconhecimento de categorias infra-específicas para Rhamnus sphaerosperma no presente trabalho.

Em revisão das espécies neotrópicas do gênero Rhamnus, Johnston \& Johnston (1978) reconheceu quatro variedades para Rhamnus sphaerosperma Swartz, diferenciando-as com base em caracteres morfológicos de folhas, flores e frutos; na descrição da variedade pubescens, entretanto, algumas características relacionadas pelo autor (folhas glabras ou com tricomas esparsos na face superior, menos concentrados na inferior; ovário e frutos pilosos, raramente glabros) não estão de acordo com a variabilidade morfológica referida por Bastos (1993), bem como a observada no material presentemente examinado (folha não glabra, em geral, moderadamente a muito pilosas e com tricomas mais concentrados na face inferior; a superior, quase glabra ou moderada até muito pilosa; ovário e frutos glabros). Em alguns destes aspectos, como no tamanho de estípulas e na indumentação de folhas e frutos, observa-se uma sobreposição a outras variedades, como a mesoamericana, sobretudo se incluirmos os indivíduos aqui analisados. Com base nestes aspectos, torna-se difícil a separação de variedades como proposto por Johnston \& Johnston (1978), preferindo-se não reconhecer a divisão de $R$. sphaerosperma em categorias infra-específicas.

Quanto à anatomia, a maior parte dos caracteres observados na madeira de Rhamnus sphaerosperma concorda com o descrito por Record (1939), Record \& Ress (1949) e Metcalfe \& Chalk (1972), para a família Rhamnaceae e gênero Rhamnus.

Cabe acrescentar, entretanto, que a presença de apêndices nos elementos de vaso não constava na literatura consultada. O material estudado também apresenta raios mais largos (1- 
5 células) e mais altos (1-50) do que o referido por Record (1939) em sua descrição do gênero (até 4 células de largura e 40 células em altura), embora o valor médio calculado para a altura esteja dentro do limite mais comum, considerado pelo autor (até 25 células). Ainda com relação aos raios, cabe destacar que sua freqüência (6-9-14/mm), resulta um pouco maior do que os valores apresentados por Metcalfe \& Chalk (1972) em sua descrição geral (4-10/mm); o valor médio, todavia, fica dentro de tal intervalo. A altura dos raios unisseriados (1-5-19 células) é também maior do que a referida pelo mesmo autor (raios unisseriados escassos ou comumente com 1 ou 2 células de altura).

A presença de elementos vasculares numerosíssimos, curtos, de pequeno diâmetro, com placas de perfuração simples, arranjados em múltiplos (ao menos parcialmente) e com espessamentos espiralados na parede, comum em espécies xeromórficas, é referido por inúmeros autores como de valor adaptativo em condições de estresse hídrico (Webber, 1936; Record \& Ress, 1949; Carlquist, 1975; Carlquist \& Hoekman, 1985; Baas \& Schweingruber, 1987; Lindorf, 1994). Tais características, entretanto, não estão de acordo com a fisionomia da planta, pois, exceto pelos tricomas, nenhum outro caráter xeromórfico é reconhecido. Nas condições atuais, tais caracteres não podem ser interpretados como de valor adaptativo para a espécie, uma vez que não se verifica carência de água em sua área de ocorrência; como lembrado por Johnston \& Johnston (1978), as espécies neotropicais do gênero ocorrem preferencialmente em solos muito úmidos.

As características acima mencionadas são comuns na família, sobretudo a presença de espessamentos espiralados e de placas de perfuração simples; uma vez fixadas no processo evolutivo - e não sendo desvantajosas -, tais características lograram persistir naturalmente na estrutura anatômica da espécie.

Com relação à taxonomia, a estrutura anatômica de Rhamnus sphaerosperma coin- cide com o relacionado por Record \& Ress (1949) para o subgênero Frangula, concordando, neste aspecto, com a interpretação de Johnston \& Johnston (1978), feita com base em aspectos da morfologia externa.

\section{BIBLIOGRAFIA}

Bastos, N. R. A família Rhamnaceae R. Br. no RS: gênero Rhamnus L. Pesquisas-Botânica, São Leopoldo, n. 44, p. 83-94, 1993.

Baas, P., Schweingruber, F. H. Ecological trends in wood anatomy of trees, shrubs and climbers from Europe. IAWA Bull., v. 8, p. 245-274, 1987.

Burger, L. M., Richter, H. G. Anatomia da madeira. São Paulo: Ed. Nobel, 1991. 154 p.

Carlquist, S. Ecological strategies of xylem evolution. Berkeley: University of California Press, 1975. 259p.

Carlquist, S., Hoekman, D. A. Ecological wood anatomy of the woody southern Californian flora. IAWA Bull., v. 6, n. 4, p. 319-347, 1985.

Copant - Comissão Panamericana de Normas Técnicas: Descrição macroscópica, microscópica e geral da madeira - esquema I de recomendação. Colômbia, 1973. 19 p. (COPANT 30).

Corrêa, M. P. Dicionário das plantas úteis do Brasil e das exóticas cultivadas. Rio de Janeiro: Imprensa Nacional, 1926. v. 1.747 p.

Dujardin, E. P. Eine neue Holz-Zellulosenfaerbung. Mikrokosmos, n. 53, 1964, p. 94.

Johnston, M. C., Johnston, L. V. A. Rhamnus. Flora Neotropica. New York, 1978.96 p.

Johnston, M. C., Soares, M. A. F. Ramnáceas. In: Reitz, R. Flora Ilustrada Catarinense. Itajaí: Herbário Barbosa Rodrigues, $1972.50 \mathrm{p}$.

Lindorf, $\mathrm{H}$. Eco-anatomical wood features of species from a very dry tropical forest. IAWA Bull., v. 15, p. 361-376, 1994.

Marchiori, J. N. C. Estudo anatômico do xilema secundário de algumas espécies dos gêneros Acacia e Mimosa, nativas no Estado do Rio Grande do Sul. Curitiba: UFPR, 1980. 186f. Dissertação (Mestrado em Engenharia Florestal) Universidade Federal do Paraná, 1980.

Marchiori, J. N. C. Fitogeografia do Rio Grande do Sul: embasamento florístico. Porto Alegre: Ed. EST, 2006, 40p.

Marzocca, A., Marthi, C. E. M. Las plantas cultivadas en la República Argentina. Buenos Aires: Ministerio de Agricultura y Ganaderia, 1951. v. 7. n. $120.48 \mathrm{p}$.

Metcalfe, C. R., Chalk, L. Anatomy of the Dicotyledons. Oxford: Clarendon Press, 1972. 1500p. 
Radford, A. E., Dickson, W. C., Massey, J. R., Bell, C. R. Vascular Plant Systematics. New York: Harper \& Row, 1974. 891p.

Rambo, B. O Elemento andino no pinhal riograndense. Anais Botânicos do Herbário "Barbosa Rodrigues", n. 3, p. 7-39. 1951.

Record, S. J. American woods of the family Rhamnaceae. Tropical Woods, n. 58, p. 6-24, 1939.

Record, S. J., Hess, R. W. Timbers of the New World. New Haven: Yale University Press, 1949. 640p.

Souza, V. C., Lorenzi, H. Botânica sistemática: guia ilustrado para identificação das famílias de
Angiospermas da flora brasileira, baseado em APG II. Nova Odessa: Instituto Plantarum, 2005. p. 389-391.

Tortosa, R. D. Flora fanerogámica argentina: Rhamnaceae. Córdoba: Programa Proflora (Conicet), Museu Botânico, 1995. fascículo 9. $18 \mathrm{p}$.

Webber, I. E., The woods of sclerophyllous and desert shrubs and desert plants of California. American Journal of Botany, v. 23, p. 181-188, 1936. 